\title{
Benchmarking energy performance of industrial small and medium-sized enterprises using an energy efficiency index: Results based on an energy audit policy program
}

Elias Andersson, Oskar Arfwidsson and Patrik Thollander

The self-archived postprint version of this journal article is available at Linköping University Institutional Repository (DiVA):

http:/ / urn.kb.se/ resolve?urn=urn:nbn:se:liu:diva- 147376

N.B.: When citing this work, cite the original publication.

Andersson, E., Arfwidsson, O., Thollander, P., (2018), Benchmarking energy performance of industrial small and medium-sized enterprises using an energy efficiency index: Results based on an energy audit policy program, J ournal of Cleaner Production, 182, 883-895.

https:// doi.org/ 10.1016/j.jclepro.2018.02.027

Original publication available at:

https:// doi.org/ 10.1016/j.jclepro.2018.02.027

Copyright: Elsevier

http:// www.elsevier.com/

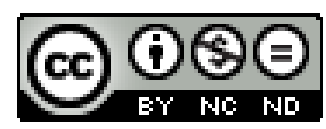


Benchmarking energy performance of industrial small and mediumsized enterprises using an energy efficiency index: Results based on an energy audit policy program

Elias Andersson ${ }^{a *}$

Linköping University

58183 LINKÖPING

Email: elias.andersson@liu.se

Oskar Arfwidsson ${ }^{\mathrm{a}}$

Linköping University

58183 LINKÖPING

Email: arfwidsson.oskar@gmail.com

Patrik Thollander ${ }^{\mathrm{a}}$

Linköping University

58183 LINKÖPING

Email: patrik.thollander@liu.se

aDepartment of Management and Engineering, Division of Energy Systems, Linköping University, SE58183

*Corresponding author. 


\title{
Abstract
}

Improved energy efficiency among industrial companies is recognized as a key effort to reduce emissions of greenhouse gases. In this context, benchmarking industrial energy efficiency plays an important part in increasing industrial companies' awareness of their energy efficiency potential. A method for calculating an energy efficiency index is proposed in this paper. The energy efficiency index is used to benchmark the energy performance of industrial small and medium-sized companies' support and production processes. This enables the possibility to compare the energy performance of single energy end-use processes. This paper's proposed energy efficiency index is applied to energy data from 11 sawmills that participated in the Swedish national energy audit program. The index values were compared with each sawmill's energy saving potential, as stated in the energy audits. One conclusion is that the energy efficiency index is suitable as an energy strategy tool in industrial energy management and could be used both by industrial SMEs and by governmental agencies with an auditing role. However, it does require a harmonized categorization of energy end-use processes as well as quality assured energy data. Given this, a national energy end-use database could be created to facilitate the calculation of an energy efficiency index.

\author{
Nomenclature \\ A temp Total heated floor area \\ BAT Best Available Technique \\ DEA Data Envelopment Analysis \\ EEI Energy Efficiency Index \\ $E_{\text {EItal, } j} \quad$ Total Energy Efficiency Index for site $j$ \\ EEM Energy Efficiency Measure \\ EEU Energy End-Use \\ KPI Key Performance Indicator \\ $\mathrm{KPI}_{\mathrm{i}, j} \quad$ Key Performance Indicator for process $i$ at site $j$ \\ $\mathrm{KPI}_{\text {ref,i }} \quad$ Reference value of Key Performance Indicator for process $i$ \\ MPI Malmquist Productivity Index \\ $\mathrm{PS}_{i, j} \quad$ Average percentage of energy end-use of process $i$ at site $j$ \\ SEAP Swedish Energy Audit Program \\ SEC Specific Energy Consumption \\ SFA Stochastic Frontier Analysis \\ SMEs Small and Medium-sized Enterprises
}

\section{Introduction}

Combating climate change remains one of the biggest challenges of our times. Up to a third of the world's $\mathrm{CO}_{2}$ emissions emanate from manufacturing industry (International Energy Agency, 2007). In Sweden, industry accounts for almost $40 \%$ of the total energy end-use (EEU), and the share of fossil fuels in the industry sectors represents almost 20\% of the national industrial EEU (Swedish Energy Agency, 2017). Of the industry sector's EEU, small and medium-sized enterprises' (SME) share is around $20 \%$. Improved energy efficiency within both large enterprises and SMEs thus plays a key role in mitigating climate change. This is reflected in the EU's target to reach $20 \%$ increased energy efficiency, established through the Energy Efficiency Directive's (2012/27/EU) set of binding measures to reach the targets (European Commission, 2012). With 2020 around the corner, an update to the energy efficiency target of $30 \%$ by 2030 has been proposed (European Commission, 2016).

Besides reducing greenhouse gas emissions, energy efficiency measures (EEMs) in the manufacturing industry also have the potential to increase companies' profitability. Industrial companies do not, however, always implement EEMs, even though they are cost-effective. This difference between the actual level of energy efficiency and the potentially optimal level has been denominated the energy 
efficiency gap (Hirst and Brown, 1990; Jaffe and Stavins, 1994). The non-implementation of seemingly cost-effective EEMs is due to the existence of market barriers (Hirst and Brown, 1990). Overcoming barriers through e.g. energy service contracting is only feasible for certain types of companies (Sorrell, 2007).

Further, the energy efficiency potential has been shown to be larger if energy management practices are included as well (Backlund et al., 2012; Paramonova et al., 2015). A recurrent theme within energy management, as found by Schulze et al. (2016), is control of energy performance, which includes aspects such as the defining and application of energy-related key performance indicators (KPIs) and benchmarking. Benchmarking can be conducted internally or externally. Historical benchmarking or company-wide benchmarking are possible internal activities, while industry benchmarking could be external (Peterson and Belt, 2009). Industrial benchmarking of energy performance allows companies to compare their energy use with other companies or with a reference value.

For industrial SMEs, a need has been identified for a simple, yet fair, energy efficiency benchmarking tool (Kimura et al., 2015). A comparison might be more accurate at a disaggregated level, i.e. between processes or equipment, but at the same time would demand more granulated energy data. Acquiring this often requires a great deal of time, a scarce resource for many SMEs. Industrial SMEs would nonetheless benefit from benchmarking of energy performance, especially at process level, as it might be used to identify energy efficiency potentials (Laurijssen et al., 2013; Xu et al., 2009).

An elementary way to determine the energy performance of a process is to calculate the specific energy use (SEC), often by dividing the energy use by the produced outputs (European Commission, 2009). SEC can be a useful measure of energy efficiency for one individual process, but when a system consisting of multiple processes is studied a value of each process could be weighted in an energy efficiency index (EEI) that represents multiple processes (Rietbergen and Blok, 2010). An EEI can be used to monitor energy performance and for internal or external benchmarking. Studies have used various EEls in different ways and applications (e.g. Morfeldt and Silveira, 2014; Saygin et al., 2011; Spiering et al., 2015). Notably, each of these studies not only had different applications but also used unique EEls.

The aim of this paper is to develop a method to calculate an EEI for estimation of industrial SMEs' total energy performance as well as the energy performance of individual EEU processes. The proposed method is applied to small and medium-sized sawmills using data from the Swedish Energy Audit Program (SEAP). Studies have looked into the benchmarking of energy performance in different contexts as well as levels of aggregation. While benchmarking of energy performance among industrial SMEs has been studied before (cf. Hasanbeigi et al., 2012; Kannan and Boie, 2003; Meyers et al., 2016; Prashar, 2017; Viesi et al., 2017; Önüt and Soner, 2007), this is to the authors' knowledge the first time energy data from a national energy audit program has been used for benchmarking industrial SMEs' energy performance. The structure of the paper is as follows. First, a literature review of various uses of an energy efficiency index and benchmarking of energy use is conducted. Second, the method adopted for the study is outlined. Third, results and analysis are presented, followed by a concluding discussion with recommendations for further studies.

\section{Benchmarking energy efficiency}

The main concept of energy benchmarking is to assess a defined system's energy performance against a reference system (Ke et al., 2013). The motivation for conducting energy efficiency benchmarking might vary, where one motivation is the awareness of the energy performance of a company compared to its peers, which might promote improvement actions (Swedish Standards Institute, 2012a). In an industrial context, different measures for defining energy performance may have different applications, e.g. thermal efficiency for a piece of equipment in an industrial operation, trends in the energy use of a facility compared to others, or in policies to evaluate regulatory performance (Tanaka, 2008). Given a reliable benchmarking value of where an industrial company 
stands against its peers, an indication can be achieved of areas in which the company should improve, which is especially relevant for energy-intensive industries (Eggleston, 2015). Benchmarking energy performance of production processes is often an intricate matter, as industrial manufacturing systems are generally complex and vary from plant to plant. This is one reason why benchmarking of energy performance for production processes is less developed than for buildings, as made evident by for example the Energy Declaration of Buildings Act in Sweden, which enables comparison of different buildings' energy performance. For energy performance benchmarking in the building sector, Chung (2011) reviewed methods for benchmarking systems to identify bad energy performance buildings. Further, more advance benchmarking at end-use level for specific building components make it possible to identify and assess potential energy efficiency improvements (Mathew et al., 2008; Mills, 2016). A benchmarking study with a process-based approach in the coal mining industry by Wang et al. (2016) showed substantial electricity efficiency potential.

For the industrial sector, Table 1 presents an overview of a number of studies related to energy performance benchmarking. The benchmarking procedure varies in terms of level of aggregation, from a multi-national level to a process level.

Saygin et al. (2011) and Azadeh et al. (2007) investigated the energy efficiency of energy-intensive industries on an aggregated level for a country-wide comparison. Meyers et al. (2016) presented an overview of energy performance benchmarks of different products in the food and beverage sector in different countries and regions. Other studies have made comparisons of industrial companies or industrial sectors between different regions within a country (Bernard and Côté, 2005; Han et al., 2014; Xue et al., 2015).

Less aggregated benchmarking for manufacturers of aluminium was carried out by Aguirre et al. (2010), where an energy-production signature was used. Other studies, such as Boyd (2016), Oh and Hildreth (2014) and Blomberg et al. (2012), also adopt a site-level benchmarking approach. Another type of site-level approach was taken by Nouri et al. (2013), where different stages of the implementation of EEMs were studied to evaluate companies' performance.

On a more detailed level, energy efficiency has been benchmarked at process level by a number of studies (e.g. Giacone and Mancò, 2012; Laurijssen et al., 2013; Spiering et al., 2015; Worrell and Price, 2006; Xu et al., 2009). Ke et al. (2013) applied a process-based energy benchmarking for the cement industry. Mateos-Espejel (2010) also conducted benchmarking at process level, comparing a case study with the pulp and paper sector's average energy use in processes in order to strategically identify which processes to search for energy saving potentials.

Table 1: Different studies' aggregated levels of energy benchmarking. The method for benchmarking is also shown. Key for method: $S E C=$ specific energy consumption, DEA = Data Envelopment Analysis, MPI = Malmquist Productivity Index, SFA = Stochastic Frontier Analysis.

\begin{tabular}{|l|c|c|c|c|}
\hline Study & $\begin{array}{c}\text { Multi- } \\
\text { national level }\end{array}$ & $\begin{array}{c}\text { National/ } \\
\text { regional level }\end{array}$ & Site-level & Process level \\
\hline (Aguirre et al., 2010) & & & DEA & \\
\hline (Azadeh et al., 2007) & & DEA, other & & \\
\hline (Boyd, 2016) & & & Other & \\
\hline (Bernard and Côté, 2005) & & Other & & \\
\hline (Blomberg et al., 2012) & & & DEA & \\
\hline (Ke et al., 2013) & & & & SEC \\
\hline (Giacone and Mancò, 2012) & & & & Other \\
\hline (Han et al., 2014) & & DEA+MPI & & \\
\hline (Hasanbeigi et al., 2012) & & & SEC & \\
\hline
\end{tabular}




\begin{tabular}{|l|c|c|c|c|}
\hline (Laurijssen et al., 2013) & & & & SEC \\
\hline (Mateos-Espejel et al., 2010) & & & & Other \\
\hline (Meyers et al., 2016) & & SEC & & \\
\hline (Morfeldt and Silveira, 2014) & SEC, DEA+SFA & & & \\
\hline (Nouri et al., 2013) & & & DEA & \\
\hline (Oh and Hildreth, 2014) & & & DEA+SFA & \\
\hline (Saygin et al., 2011) & SEC & SEC & & \\
\hline (Spiering et al., 2015) & & & & SEC \\
\hline (Worrell and Price, 2006) & & & SEC & SEC \\
\hline (Xu et al., 2009) & & SEC & & SEC \\
\hline (Xue et al., 2015) & & DEA+MPI & & \\
\hline (Önüt and Soner, 2007) & & & DEA & \\
\hline
\end{tabular}

The studies in Table 1 show a broad range of applications of energy performance benchmarking. When modelling energy demand, the models used are generally differentiated as either top-down or bottom-up (Fleiter et al., 2011). The results of one type of analysis cannot be said to conform to the other, as both approaches have their own characteristics (Wilson and Swisher, 1993). A top-down approach is often adopted for benchmarking between countries or sectors, using national data or similar. For energy savings, the European Standard EN 16212:2012 on energy efficiency and saving calculations describes the top-down method procedure as determining energy savings from aggregated statistical figures at a national or sectoral level (Swedish Standards Institute, 2012b). Energy indicators and benchmarking at a more disaggregated level, however, generally require more detailed data (International Energy Agency, 2014). The calculation of energy savings with a bottomup approach has the specific end-user actions in focus.

Different tools for benchmarking industry energy performance have been developed. The EU-funded project ODYSSEE-MURE administers a database containing energy efficiency indicators of top-down national data (ODYSSEE-MURE, 2017). The database allows comparisons between countries and different sectors, such as transport, households and services, and industry. In the United States, the Environmental Protection Agency's voluntary labelling program ENERGY STAR also provides a benchmarking tool for industrial plants to track their energy performance (ENERGY STAR, 2017). Worrell and Price (2006) developed a benchmarking tool, BEST (Benchmarking and Energy Savings Tool), and applied it to two iron and steel plants. In Sweden, a nation-wide database exists called ENIG that consists of multiple energy performance indicators, such as $\mathrm{MWh} /$ produced unit, where individual companies can compare their energy performance with that of their peers (SWEREA, 2017). The performance indicators, as reported by each company, constitute the database and each company remains anonymous. Ensuring confidentiality of data is often a prerequisite for companies to participate in benchmarking programs - to what degree depends on the level and type of data needed for the benchmark (Eggleston, 2015).

The selection of reference values for benchmark practices is multi-faceted. The reference value can for example be based on "best practice" of the selected population for the benchmarking (cf. Aguirre et al., 2010). These types of values are useful in order to determine how a company compares to the top performer in a sector, or to the best practice techniques. The best practice reference value can also be derived from the EU best available techniques (BAT) reference documents. It is important to note, however, that even if they are updated regularly, they are sometimes outdated, and documents do not exist for certain industrial sectors. Furthermore, it is not possible for a company to reach the best practice, even theoretically, if external factors that affect energy performance, such as climate, raw material quality or product quality, are not normalized. As far as is reasonable, these external 
factors should be accounted for as stated in the European Standard on Energy efficiency benchmarking EN 16231:2012 (Swedish Standards Institute, 2012a).

Another possible reference value to use is the average energy efficiency (Boyd, 2016). This can be set from the studied population, or from the industrial sector in general. While benchmarking to an average value determines whether the benchmarked entity is better or worse than the average, energy efficiency targets in a benchmarking program can be set at a higher performance level, e.g. the first quartile.

Regarding system boundaries, some studies use the final EEU at processes or sites (cf. Ke et al., 2013), while others factor in different energy carriers, for example by making a distinction between electricity and fuels (cf. Hasanbeigi et al., 2012). Sometimes heat is also distinguished (cf. Laurijssen et al., 2013). Moreover, others calculate the primary energy use (cf. Laurijssen et al., 2013; Worrell and Price, 2006).

Longitudinal energy performance benchmarking is more common for internal benchmarking than external benchmarking, using a reference value from a given reference year. By tracking energy efficiency over time, a company can monitor its progress towards a pre-set target. The advantage of self-monitoring is that plant-specific properties remain the same during the comparison period (Boyd, 2016). It does not, however, provide information about how the company compares to its peers.

Indicators used for benchmarking purposes can be either economic or physical. Economic indicators are often referred to as energy intensity and are measured in economic terms such as GDP (Bunse et al., 2010; International Energy Agency, 2014). Data envelopment analysis (DEA), a non-parametric statistical approach, is commonly used in economic analyses. Other methods are the stochastic frontier analysis (SFA) and the Malmquist Productivity Index (MPI). Refer to the cited references in Table 1 for a more detailed explanation of these methods. Physical indicators, on the other hand, have a physical denominator, where one commonly used measure is specific energy consumption (SEC), defined as the amount of energy used per unit of output (European Commission, 2009).

Capturing an energy efficiency trend in an industrial context is difficult, as an EEI is usually affected by factors that are not connected to a change in energy efficiency. If energy intensity is used, there is a risk that market dynamics will be reflected rather than energy efficiency changes (Morfeldt and Silveira, 2014). However, by neglecting economic aspects in an EEI, it is difficult to capture differences in, for example, product quality. Other possible influencing aspects are local-specific factors, such as environment or the size of the site.

\section{Method}

In order to develop a method for calculating an EEI for industrial SMEs, six interviews were carried out: five interviews with actors at four different governmental agencies and one interview with an energy audit company. In addition, a meeting with a reference group was held during the development of the method. The interviews were conducted either by personal meeting or by phone, and followed a semi-structured interview guide (Kvale and Brinkmann, 2009). The predominant goal of the interviews was to obtain the interviewees' input on how to successfully benchmark industrial SMEs' energy performance. It was also important to investigate what type of EEl would be of use in their specific roles, e.g. in strategies for auditing. The interview questions concerned the respondents' experience of benchmarking industrial EEU, what benefits they could identify, possible barriers to and drivers for benchmarking, and the recommended level of detail of the benchmark, all in the context of industrial SMEs. The respondents had a coherent perspective that a bottom-up approach with EEU distributed on support and production processes is a prerequisite for fair benchmarking of energy performance; however, it also involves challenges such as data confidentiality and process heterogeneity. Based on the input from the interviews, a method for calculating an EEl for industrial SMEs was developed. 
Energy data from the SEAP was used to calculate the EEI. Participating SMEs received a subsidy to conduct an energy audit, and over 700 industrial SMEs participated in the SEAP during the program period between 2010 and 2014. No formal requirements were placed on the energy auditors, but the EEU was to be divided into ten categories, with nine different support processes (inspired by Söderström, 1996), and production processes were considered as a whole. This was reported by each company to the Swedish Energy Agency, together with the energy auditors' identified EEMs, which resulted in a database consisting of all participants' EEUs and EEMs. For each company, the energy audit report was enclosed in the reporting of data. In addition to the EEU processes, information about the companies' total floor area and total heated area were also included in the database.

Since the database itself did not provide all the necessary data for the calculation of the EEI, the lacking necessary data had to be collected. The additional information needed was the number of employees and the produced volume of goods. Also, the EEU for production processes had to be divided into subprocesses according to the defined categorization. Thus, the energy audits were studied in depth and only data from one sub-sector of participating companies was studied, namely companies categorized according to the NACE code C16 (European Commission, 2015): "Manufacture of wood and of products of wood and cork, except furniture; manufacture of articles of straw and plaiting materials". The companies will from here on be referred to as sawmills. The choice of one sub-sector also had another important aspect: to test and validate the model on companies that may be similar to each other regarding production processes.

This resulted in a first selection of 31 companies, consisting of all sawmills participating in the SEAP. The sawmills whose energy audits did not contain the information needed for the calculation of the $\mathrm{EEI}$, or for which data were not otherwise accessible, were excluded. This selection narrowed the number of companies down to 11 . For all except three companies, the energy audit provided information about the number of employees and the produced volume of goods. For one company, the produced volume of goods had to be derived from their website, and for three companies, the number of employees was obtained from an information service.

For the 11 sawmills, an EEI was calculated according to the developed model, using both their EEU for every process before implementation of measures, and their EEU after implementation of suggested EEMs (assuming every measure is implemented), in order to get a "before-after" comparison of the EEl. A comparison was also made with each company's total energy saving potential for the processes included in the EEI. For further comparison, the EEI was also calculated in its simplest form for the entire sawmill sites, similar to the EEI in the European Commission's reference document for Energy Efficiency (European Commission, 2009).

\section{Results and analysis}

\subsection{Method for calculating an energy efficiency index for an industrial sub-sector}

Many of the interviewees raised concerns about the difficulty of achieving a fair comparison between industrial companies due to their diversity. To take this into account, benchmarking should focus on a specific industrial sub-sector with similar processes, or be carried out at process level.

The interviewees further suggested that an energy indicator based on a physical denominator, such as SEC, would be more suitable for benchmarking EEU processes than an economic indicator. This is also noted by Laurijssen et al. (2013). A three-step method was followed to systematically calculate the EEI for an industrial sub-sector, as shown in Figure 1. 


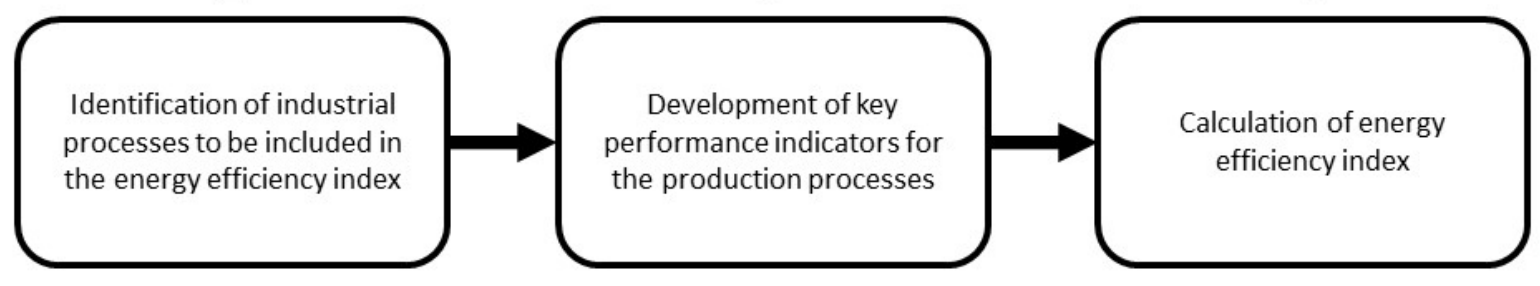

Figure 1: Three-step method for calculating an EEI for an industrial sub-sector.

The first step in the preliminary method involves defining which industrial EEU processes to include in the calculation of the EEl. This should be able to take the energy use of the chosen processes into account, making it measurable, or in other ways obtainable, with a reasonable amount of effort. Someone conducting an energy audit should be able to divide the energy use according to the set definition of processes. Certain rare production processes, which are only applicable to a few companies, might be divided into a category designated "Other production processes".

A selection of processes can for example follow the concept of unit processes, as presented by Söderström (1996), or consist of a number of connected processes specific to an industrial sub-sector.

After defining industrial EEU processes in step one, step two consists of developing KPIs for the chosen processes. Bunse et al. (2011) presented a number of energy efficiency indicators used in the scientific literature, among them economic, physical, macro-economic, thermodynamic and hybrid indicators. May et al. (2015) presented a method in seven steps to develop KPIs at industrial companies, intended to be customized for an individual site's specific production processes.

The third and last step consists of calculating an EEl for the studied sub-sector, using the chosen processes with the corresponding KPIs developed in the preceding step. An indexed value is calculated for each included process by dividing the value of the KPI of a process by a reference value. The reference value can for example be set as the mean or some percentile of the distribution (Boyd, 2016). It could also be set from the best practice or the best performer of each process from the sample of companies. Best practice values for sawmills exist, but at process level the only attainable value is for the drying process, while the other processes would have to use the best performer in the sample of companies. Given the uncertainty of data quality from the samples, data points that seem reasonable but are potentially skewed will have a larger impact on EEls if the reference value is set according to the best performer since the other companies' values will be dependent on that single data point rather than on an average. Thus, in this paper the average value was chosen, consisting of the sub-sector's average value of the KPI of the same process. It is important to note that, due to the small sample of companies and data points, skewness of data will still have a large impact on the EEI, but not as large as if best performer had been used. Equation 1 shows the calculation of EEI for an EEU process:

$E E I_{i, j}=\frac{K P I_{i, j}}{K P I_{r e f, i}}$

Where:

$\mathrm{EEI}_{\mathrm{i}, \mathrm{j}}=\mathrm{EEI}$ for process $i$ at site $j$,

$\mathrm{KPI}_{i, j}=\mathrm{KPI}$ for process $i$ at site $j$,

$\mathrm{KPI}_{r e f, i}=$ average sub-sectoral value of $\mathrm{KPI}$ for process $i$.

All the processes are then added together and the EEI for an entire site is calculated according to Equation 2. 
$E E I_{\text {total }, j}=\sum_{i=1}^{n} P S_{i, j} \cdot E E I_{i, j}$

Where:

$\mathrm{EEI}_{\text {total, } \mathrm{j}}=$ total $\mathrm{EEI}$ for site $j$,

$\mathrm{PS}_{i, j}=$ the percentage of total EEU of process $i$ at site $j$,

$\mathrm{n}=$ total number of processes included in the EEI.

The sum of $\mathrm{PS}_{i, j}$ of all included processes adds up to $100 \%$. The inclusion of this term implies a more reasonable weighing of processes into $\mathrm{EEI}_{\text {total, }}$ i.e. without this term a process with generally low EEU, such as cooling, would have equal impact on the total EEI as a process with generally high EEU, such as compressed air.

From Equation 2, the average indexed value of all companies will most likely be distinct from 1, since the processes are balanced to each specific site's EEU for each process; the processes are not balanced in the same way. This could result in multiple companies getting a too low (or high) indexed value, and theoretically, all included companies could have an indexed value below (or above) 1 , even if that is unlikely. In order to balance the indexed value to an average value of 1 , each company's total EEl is multiplied by a factor according to Equation 3.

$E E I_{\text {weighted total }, j}=E E I_{\text {total }, j} \cdot\left(\frac{m}{\sum_{j=1}^{m} E E I_{\text {total }, j}}\right)$

$\mathrm{EEI}_{\text {weighted total, } \mathrm{j}}=$ Total weighted EEI for site $j$.

$\mathrm{m}=$ total number of companies.

As evident, the proposed method for calculating an EEI adopts a bottom-up approach. The EEI allows an indexed value to be achieved for both the entire site and for single EEU processes, similar to the tool developed by Worrell and Price (2006). Industrial companies with partly different production processes can achieve a fair benchmark by only comparing similar processes. The main distinction between the preliminary method proposed in this paper and the one developed by Worrell and Price (2006) is that they include the production quantity for each process when aggregating the index for the entire site. This is not applicable to support processes, and for production processes such information is not always accessible or hard to access, especially in industrial SMEs. Thus, the term $\mathrm{PS}_{i, j}$ is proposed instead, which is applicable to both support and production processes.

The EEI is constructed such that a low value of a company's EEI implies that the EEU processes are energy efficient, while a high value implies the opposite.

\subsection{Applying the index to small and medium-sized sawmills}

The final energy use in Sweden for wood products was 7.4 TWh in 2013 (Swedish Energy Agency, 2017). The production of wood products in the same year was $16.0 \mathrm{Mm}^{3}$ from softwood (Swedish Forest Agency, 2014), resulting in an average SEC of $460 \mathrm{kWh} / \mathrm{m}^{3}$ produced goods. This does not include hardwood, which is less commonly used by Swedish sawmills. A study by Andersson et al. (2011) shows an average value of $400 \mathrm{kWh} / \mathrm{m}^{3}$ produced goods at the studied sawmills. The companies in this study have an average SEC of $390 \mathrm{kWh} / \mathrm{m}^{3}$.

In the SEAP, the support processes were categorized according to Table 2. Table 2 also shows the selected KPIs for this study. The choice of KPIs was restricted to the readily available data from the SEAP database, thus a bottom-up approach for KPI development was applied (Towslee, 2015). For future use of the proposed method, other KPIs can be developed that might better normalize the values and result in a fairer comparison. 
Since this data was already provided through the database, no changes were made to the categorization of support processes.

Table 2: Support processes as presented in the SEAP and the chosen KPI for each process. Participating companies reported their total area $\left(m^{2}\right)$ and their total heated area $\left(m^{2} A_{\text {temp }}\right)$.

\begin{tabular}{|c|c|}
\hline Support processes & KPI \\
\hline Space heating & $\mathrm{kWh} / \mathrm{m}^{2} A_{\text {temp }}$ \\
\hline Lighting & $\mathrm{kWh} / \mathrm{m}^{2}$ \\
\hline Ventilation & $\mathrm{kWh} / \mathrm{m}^{2} \mathrm{~A}_{\text {temp }}$ \\
\hline Administration & kWh/employee \\
\hline Cooling & $\mathrm{kWh} / \mathrm{m}^{2} \mathrm{~A}_{\text {temp }}$ \\
\hline Tap water heating & $\mathrm{kWh} / \mathrm{m}^{3}$ sawn goods \\
\hline Compressed air & $\mathrm{kWh} / \mathrm{m}^{3}$ sawn goods \\
\hline Internal transport & $\mathrm{kWh} / \mathrm{m}^{3}$ sawn goods \\
\hline Other & $\mathrm{kWh} / \mathrm{m}^{3}$ sawn goods \\
\hline
\end{tabular}

The primary issues with the selected KPI for space heating are that it is dependent on geographical location (climate) and is affected by excess heat from EEU processes, which might vary between companies. The former can be addressed with Heating Degree Day, but since most sawmills were located in roughly the same regions in Sweden, this was deemed not to have a particular impact on the EEl. The effect on space heating from excess heat is not investigated here, but could be subject to further studies.

Regarding production processes, sawmills often have quite straightforward and linear production. Olsson et al. (2011) conducted a study where the production processes were divided into five different zones, to facilitate measuring EEU as well as benchmarking. The same division of production processes was used in this study's calculation of EEl, with the small change that energy used in the drying process was divided up into heat and electricity. This change was implemented due to the drying process accounting for the largest share of EEU in sawmills, generally around 80\% (Andersson et al., 2011). Furthermore, there is a substantial share of both heat and electricity use in the drying process, in contrast to the other support and production processes which are mainly dominated by one energy carrier. The exception is space heating, but it was not possible to make such a division due to limited accessible information. The division of production processes and the applied KPI are shown in Table 3.

Table 3: Division of production processes and the applied KPI (inspired by Olsson et al., 2011).

\begin{tabular}{|l|l|}
\hline Production processes & \multicolumn{1}{|c|}{ KPI } \\
\cline { 1 - 1 } Log sorting & \\
\cline { 1 - 1 } De-barking and sawing & \\
\cline { 1 - 1 } Drying (electricity) & \multirow{3}{*}{$\mathrm{kWh} / \mathrm{m}^{3}$ sawn goods } \\
\hline Drying (heat) & \\
\hline Regrading & \\
\cline { 1 - 1 } $\begin{array}{l}\text { Other production } \\
\text { processes }\end{array}$ & \\
\hline
\end{tabular}

A commonly used $\mathrm{KPI}$ in energy audits is $\mathrm{kWh} / \mathrm{m}^{3}$ sawn goods, and this is applicable to all production processes. The total final amount of produced sawn goods was used in the calculations. It is important to note that this KPI does not take account of the moisture content of the material. The moisture content of raw materials depends on several properties such as the heartwood-sapwood ratio, as heartwood is drier than sapwood (Taylor et al., 2002). Furthermore, the sapwood moisture content is in turn affected by the time and condition of where the logs have been stored in the forest, which 
affects the energy use in the drying process (Skog et al., 2010). Also, different end product qualities require different moisture contents. A common way to determine the moisture content is by measuring the weight difference between the green wood and the oven dry wood.

As such data, however, were unavailable, the choice of a rather simple KPI allowed for the inclusion of more sawmills in the calculation of the EEI in this paper. In future benchmarking programs, a KPI for the drying process could include moisture content.

The last step is to calculate the EEI. Figure 2 shows the resulting total EEI calculated before and after the implementation of suggested measures. When the EEI was calculated using the proposed method, the category Other for both support and production processes was not included, the former since some EEMs that belonged to more than one EEU process were often categorized as Other (such as education of employees), and were difficult to allocate correctly. The latter was not included since not every sawmill has additional production processes, such as impregnation. The energy allocated in these categories corresponded to less than $4 \%$ of the sawmills' total final EEU, and therefore did not have a significant impact on the total EEI. It is important to note, however, that further processing can be included in a benchmarking analysis between companies that have the same processes, using the proposed method.

The EEI was also calculated using the simple form as presented by the European Commission (2009), where the companies' total EEU is divided by the total amount of produced goods, and using the average value as reference value in the benchmark.

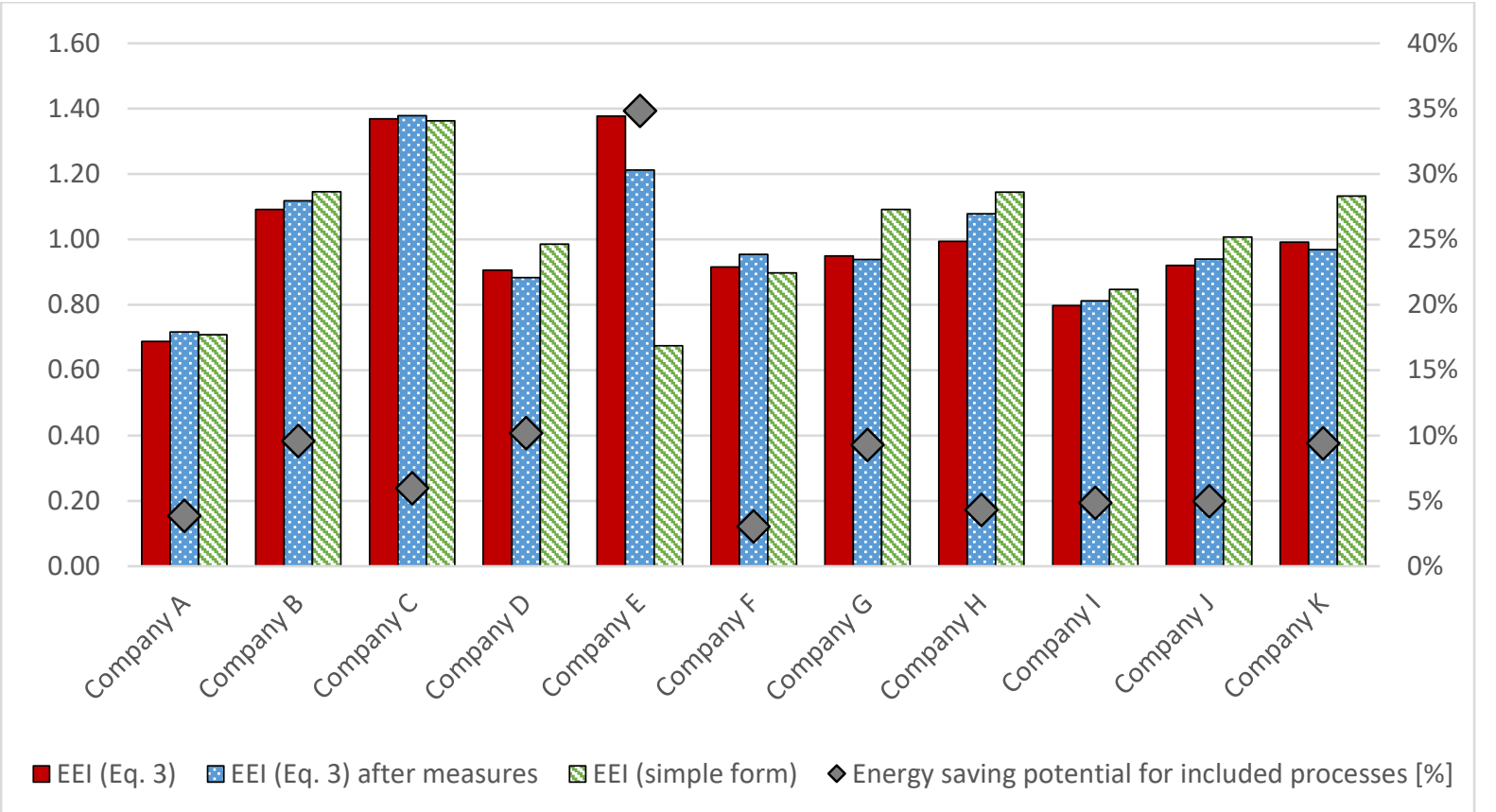

Figure 2: Resulting total EEI for all 11 sawmills included in the study, calculated by the method proposed in this paper before and after implementation of EEMs. The EEI after measures assume that all suggested EEMs in the energy audit report were implemented by the companies. The EEI was also calculated using the simple form as presented by the European Commission (2009). Furthermore, the percentage of energy saving potential for each company based on all proposed measures in the energy audits for the included processes in the EEI is shown.

Notably, as shown in Figure 2, all companies with an energy saving potential of $9 \%$ or higher receive a lower value for their EEI if all EEMs are implemented, with the exception of company B. Likewise, all companies with a $6 \%$ or lower energy saving potential increase their EEl. The reason that not every company improve their EEI is due to new reference values for each included process. Since the reference value $\left(\mathrm{KPI}_{\text {ref,i }}\right)$ for each process is dependent on the average value of all companies' KPIs, any changes in a company's KPI for a process, also changes the reference value for the same process. 
Thus, it is dependent on both the individual company's energy efficiency improvements as well as other companies' improvement, i.e. the amount of energy saved and in which processes, whether a company reduces its total EEI or not. If only one company implements EEMs, they would receive a lower value for their EEl, while all other companies would receive a slightly higher EEI value.

Comparing EEI calculated using Equation 3 with the EEI in its simple form, Company E stands out by receiving an EEI value of 0.67 when calculated in its simplest form, while achieving the highest value, 1.38, when calculated using Equation 3 (before implementation of EEMs). Company E has a very low EEU for heat used in the drying process, but a relatively high end-use of electricity in the same process. The electricity end-use in the drying process accounts for $33 \%$ of the included processes' total EEU for Company $E$, while for the other companies it is only $11 \%$, which explains why Company $E$ has such a different indexed value depending on how the EEl is calculated. Due to the term $\mathrm{PS}_{i, j}$ in Equation 3, the drying (heat) process has a larger impact on Company E's total EEl, and consequently raises the EEI value. The difference in heat and electricity use in Company E's drying process might be due to a different drying technique or errors in the energy data. The reason for this difference could not be determined from the energy audit report.

The advantage of the simple form of EEl is that it only requires two data points for each company the total amount of energy use, and the total number of produced units of goods. While these values are easily accessed, it does not capture important differences between companies, which is why an EEI where EEU processes are divided in a harmonized way for multiple companies can better reflect existing differences, as well as only comparing processes that exist in all companies.

Furthermore, assuming equally conducted energy audits regarding quality and in-depth analysis, the energy saving potential for each company should correspond roughly to their total EEl value. From Figure 2, it is evident that this is not the case, but since there is a discrepancy between both quality and number of hours spent on the energy audits, it is not possible to draw any conclusions regarding this, as this affects the number of EEMs suggested. To validate the method proposed in this paper, this should be further investigated with data where more similar energy audits have been conducted.

Moreover, the comparison between sawmills can be misleading if the energy auditors made simplifications and did not map all processes correctly, consequently placing a share of the EEU in the category "Other". As this category is not included in the calculated EEl, this allows a greater amount of energy that is not considered in the overall EEI. However, the EEU in the category "Other" was in general relatively low, on average around $2 \%$.

\subsection{Energy efficiency index for single processes at the studied sawmills}

As mentioned earlier, the index also allows benchmarking of single processes. In Table 4 the average value of each EEU process is presented.

Table 4: Average values and standard deviation for the EEU processes, produced volume, number of employees, and floor area for the sample of companies. For EEU processes, the percentage of the total average EEU is also shown.

\begin{tabular}{|c|c|c|c|}
\hline & Average value & & Standard deviation \\
\hline Space heating & $2024 \mathrm{MWh} /$ year & $(7 \%)$ & 1539 \\
\hline Lighting & $251 \mathrm{MWh} /$ year & $(1 \%)$ & 142 \\
\hline Ventilation & $230 \mathrm{MWh} /$ year & $(1 \%)$ & 212 \\
\hline Administration & $69 \mathrm{MWh} /$ year & $(0 \%)$ & 47 \\
\hline Cooling & $40 \mathrm{MWh} /$ year & $(0 \%)$ & 0 \\
\hline Hot tap water & $20 \mathrm{MWh} /$ year & (0\%) & 8 \\
\hline Compressed air & $395 \mathrm{MWh} /$ year & $(1 \%)$ & 243 \\
\hline Internal transport & $1693 \mathrm{MWh} /$ year & (6\%) & 866 \\
\hline Other & $516 \mathrm{MWh} /$ year & $(2 \%)$ & 476 \\
\hline Log sorting & $162 \mathrm{MWh} /$ year & $(1 \%)$ & 101 \\
\hline De-barking and sawing & $1155 \mathrm{MWh} /$ year & $(4 \%)$ & 482 \\
\hline Drying (heat) & $18821 \mathrm{MWh} /$ year & $(67 \%)$ & 11184 \\
\hline
\end{tabular}




\begin{tabular}{|l|ll|l|}
\hline Drying (electricity) & $2990 \mathrm{MWh} /$ year & $\mathbf{( 1 1 \% )}$ & 1944 \\
\hline Regrading & $185 \mathrm{MWh} /$ year $\quad(1 \%)$ & 86 \\
\hline Other production processes & $583 \mathrm{MWh} /$ year & $(2 \%)$ & 612 \\
\hline Produced volume & $75478\left[\mathrm{~m}^{3}\right]$ & & 51169 \\
\hline Number of employees & 44 & 14 \\
\hline $\mathbf{A}_{\text {temp }}$ & $8028\left[\mathrm{~m}^{2}\right]$ & 4012 \\
\hline Total area & $9141\left[\mathrm{~m}^{2}\right]$ & 5895 \\
\hline
\end{tabular}

Figure 3 shows the companies' resulting index for the support processes. The EEI for cooling has been excluded as only one company had reported EEU for that process.

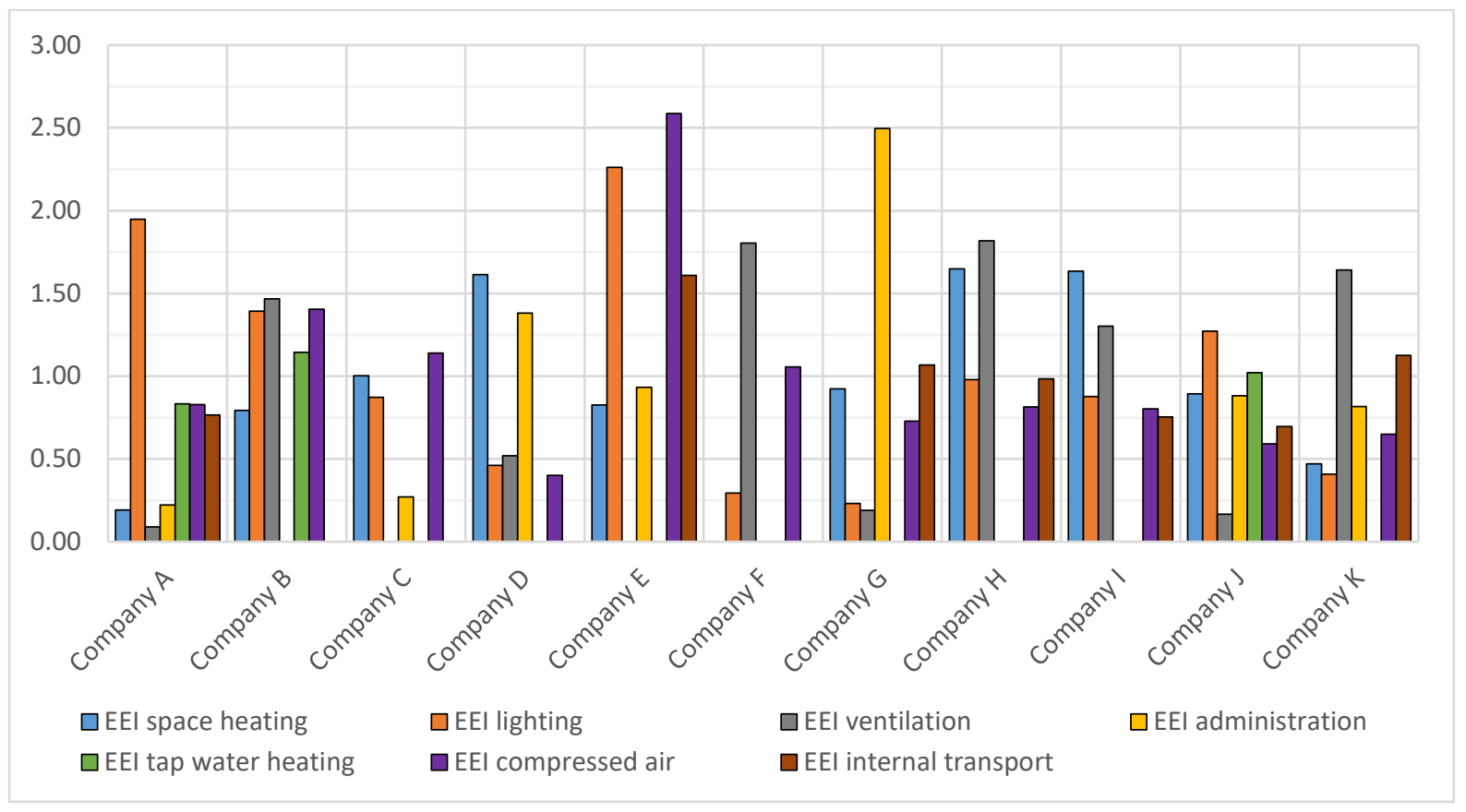

Figure 3: The resulting EEI for each included support process.

From Figure 3 it is possible to note a number of diverging values. Regarding space heating, both Company $\mathrm{A}$ (especially) and Company $\mathrm{K}$ receive low scores. One uncertainty is that the division of heating supplied to facilities and to the drying process is not always clear. It therefore has to be estimated, but neither of the energy audits explicitly explains how this was done. Regarding lighting, Company $E$ achieved a very high score. The energy audit reveals that the company uses lighting equipment with quite high power, ranging from 160 to $450 \mathrm{~W}$, which could explain the high EEI.

The companies' EEl for ventilation varies to a high degree, with a few having an extremely low value (companies $\mathrm{A}, \mathrm{G}$ and J), and others having very high values (companies $\mathrm{H}$ and $\mathrm{K}$ ). Regarding ventilation, it is generally difficult to determine how each auditor has chosen to categorize this, as processventilation is commonly used at sawmills. It could be allocated either to ventilation (support process) or to a specific production process. For the majority of the reports, it was not possible to distinguish how it was categorized. In order to achieve a meaningful and fair comparison in future benchmarking programs, it is important to agree on a common, clearly specified procedure of allocation of EEU, e.g. how to categorize process-ventilation.

Internal transport mostly relates to trucks or loaders, and a thorough description was seldom given. Compressed air generally has a large energy saving potential, which is also the case at the studied sawmills. Many of the proposed EEMs concern sealing of leakages and replacement of compressors. Lastly, administration and hot tap water generally account for small shares of each company's EEU. Table 5 shows the sawmills' energy saving potential and the percentage of potential energy savings for each support process. 
Table 5: Energy saving potential from proposed EEMs for support processes at each company, presented in MWh/year of each support process, rounded to the nearest ten. The percentage of energy saving potential corresponds to the total energy saved from all proposed EEMs. Note that Administration and Tap Water Heating have been excluded from the table, since no EEMs were given for these processes.

\begin{tabular}{|l|ll|ll|l|l|l|l|l|l|}
\hline Company & \multicolumn{2}{|c|}{$\begin{array}{c}\text { Space Heating } \\
{[\mathrm{MWh} / \text { year] }}\end{array}$} & \multicolumn{2}{|c|}{$\begin{array}{c}\text { Lighting } \\
{[\mathrm{MWh} / \text { year] }}\end{array}$} & \multicolumn{2}{c|}{$\begin{array}{c}\text { Ventilation } \\
{[\mathrm{MWh} / \text { year] }}\end{array}$} & $\begin{array}{c}\text { Compressed air } \\
{[\mathrm{MWh} / \text { year] }}\end{array}$ & $\begin{array}{c}\text { Internal transport } \\
{[\mathrm{MWh} / \text { year] }}\end{array}$ \\
\hline Company A & 0 & $(0 \%)$ & 190 & $(8 \%)$ & 0 & $(0 \%)$ & 400 & $(18 \%)$ & 0 & $(0 \%)$ \\
\hline Company B & 800 & $(34 \%)$ & 30 & $(1 \%)$ & 0 & $(0 \%)$ & 0 & $(0 \%)$ & 0 & $(0 \%)$ \\
\hline Company C & 100 & $(9 \%)$ & 50 & $(5 \%)$ & 10 & $(1 \%)$ & 30 & $(2 \%)$ & 0 & $(0 \%)$ \\
\hline Company D & 510 & $(23 \%)$ & 0 & $(0 \%)$ & 0 & $(0 \%)$ & 80 & $(4 \%)$ & 0 & $(0 \%)$ \\
\hline Company E & 10 & $(0 \%)$ & 150 & $(7 \%)$ & 0 & $(0 \%)$ & 120 & $(6 \%)$ & 0 & $(0 \%)$ \\
\hline Company F & 0 & $(0 \%)$ & 0 & $(0 \%)$ & 0 & $(0 \%)$ & 0 & $(0 \%)$ & 0 & $(0 \%)$ \\
\hline Company G & 600 & $(28 \%)$ & 30 & $(1 \%)$ & 0 & $(0 \%)$ & 50 & $(2 \%)$ & 0 & $(0 \%)$ \\
\hline Company H & 10 & $(0 \%)$ & 100 & $(9 \%)$ & 0 & $(0 \%)$ & 170 & $(15 \%)$ & 190 & $(16 \%)$ \\
\hline Company I & 540 & $(57 \%)$ & 30 & $(3 \%)$ & 80 & $(8 \%)$ & 150 & $(16 \%)$ & 150 & $(16 \%)$ \\
\hline Company J & 120 & $(5 \%)$ & 20 & $(1 \%)$ & 0 & $(0 \%)$ & 0 & $(0 \%)$ & 110 & $(5 \%)$ \\
\hline Company K & 190 & $(5 \%)$ & 30 & $(1 \%)$ & 0 & $(0 \%)$ & 120 & $(3 \%)$ & 130 & $(3 \%)$ \\
\hline Total: & $\mathbf{2 8 8 0}$ & & $\mathbf{6 3 0}$ & & $\mathbf{9 0}$ & & $\mathbf{1 1 2 0}$ & & $\mathbf{5 8 0}$ \\
\hline
\end{tabular}

Regarding the support processes, most of the companies received proposed EEMs for space heating, lighting and compressed air, as shown in Table 5. The process space heating might be misleading for some companies, as the allocation of space heat, and its measures, is uncertain. This is the case for Company B, which had a large energy saving potential, although the technical characteristics of their building envelopes had many improvement possibilities. The figures might nonetheless be exaggerated or miscalculated. For Company G's lighting figures, noting its low EEl value for lighting, it is probably the reported EEU that is incorrect; however, it is not possible to validate this from the energy audit report.

Notably, no EEMs were suggested for administration, cooling, or hot tap water. These processes account for a small share of the companies' total EEU, less than $1 \%$, explaining why there was no emphasis on investigating these processes. Furthermore, there were unexpectedly few EEMs for ventilation. As the EEU showed discrepancy with regard to the EEI, the same might apply to EEMs, where energy saving potentials for ventilation are found in measures for production processes.

The indexed values for the included sawmills' production processes are shown in Figure 4. For some sawmills, certain processes do not exist at the plant or data were unavailable. Several companies therefore do not have a value for those production processes. 


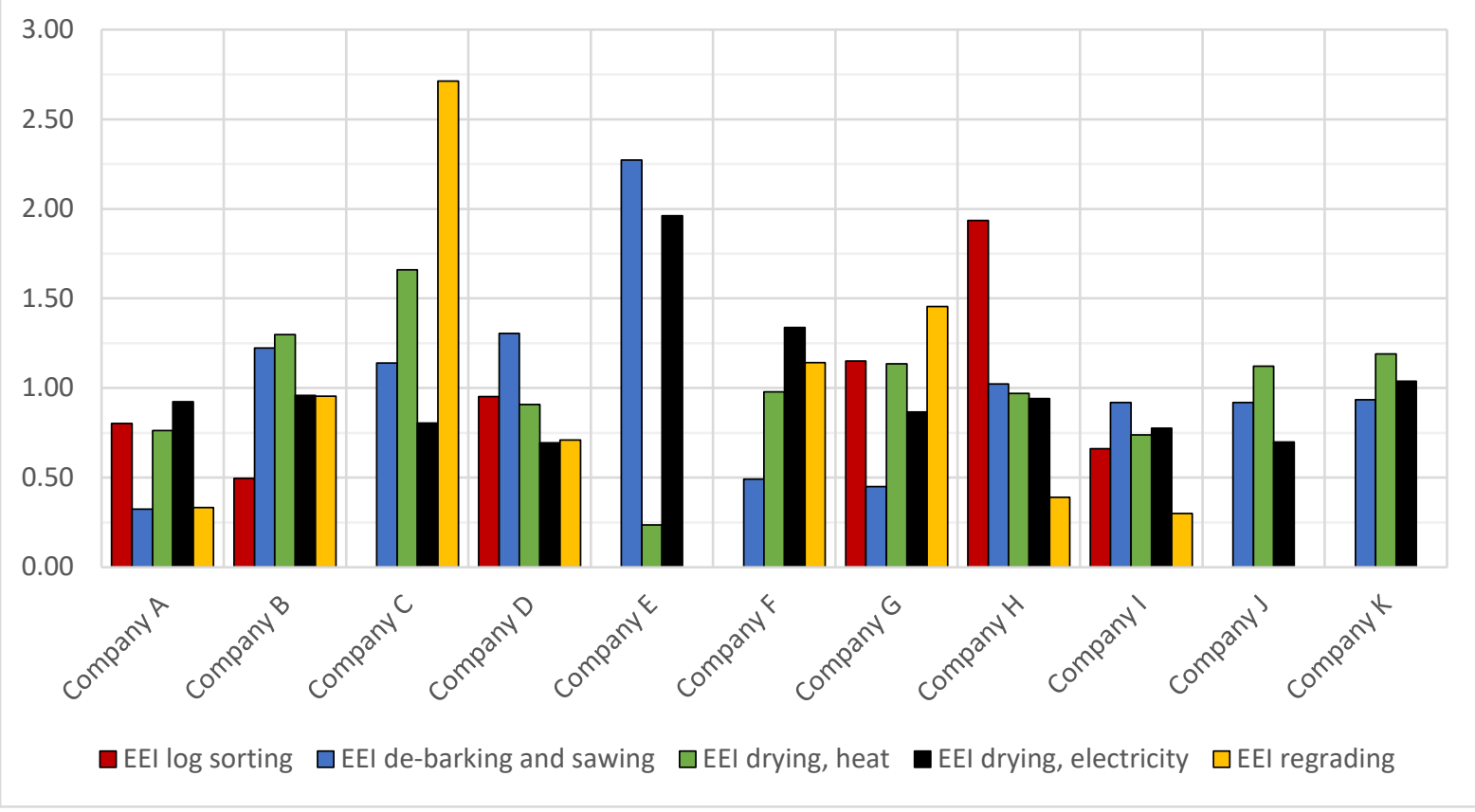

Figure 4: The resulting EEI for each included production process.

A few interesting notes for each production process can be given in respect of Figure 4. Log sorting was only measured at several companies, most likely due to the low EEU (less than $1 \%$ of total EEU) in this process in comparison to other processes. Regarding de-barking and sawing, companies $A, F$ and $G$ achieved a relatively low value, while Company $E$ stands out with a high value. The production process regrading was - similar to log sorting - not measured to a large extent among the companies. The EEI value for companies A and I for regrading indicates energy-efficient processes, while Company $\mathrm{C}$ seems to have room for improvement. The resulting EEI for the most energy-intensive production process, drying, shows that the electricity used in this process is evenly spread across the companies. Company E, however, achieves a rather high value, while at the same time having a low EEI for heat used in the same process. As mentioned earlier, this might indicate a different type of drying process technique, based on greater use of electricity rather than heat.

Table 6 shows the energy saving potential from proposed EEMs and the percentage of potential energy savings for each production process.

Table 6: Energy saving potential from proposed production-related EEMs for each company presented in MWh/year for each production process, rounded to the nearest ten. The percentage of energy saving potential corresponds to the total energy saved from all proposed EEMs for production processes included in the EEI.

\begin{tabular}{|l|ll|ll|ll|ll|ll|}
\hline Company & \multicolumn{2}{|c|}{$\begin{array}{c}\text { Log sorting } \\
\text { [MWh/year] }\end{array}$} & \multicolumn{2}{|c|}{$\begin{array}{c}\text { De-barking and } \\
\text { sawing } \\
{[\text { MWh/year] }}\end{array}$} & \multicolumn{2}{|c|}{$\begin{array}{c}\text { Drying, heat } \\
\text { [MWh/year] }\end{array}$} & $\begin{array}{c}\text { Drying, electricity } \\
\text { [MWh/year] }\end{array}$ & $\begin{array}{c}\text { Regrading } \\
\text { [MWh/year] }\end{array}$ \\
\hline Company A & 0 & $(0 \%)$ & 100 & $(5 \%)$ & 970 & $(44 \%)$ & 480 & $(22 \%)$ & 80 & $(3 \%)$ \\
\hline Company B & 3 & $(0 \%)$ & 60 & $(3 \%)$ & 850 & $(36 \%)$ & 570 & $(24 \%)$ & 60 & $(2 \%)$ \\
\hline Company C & 0 & $(0 \%)$ & 0 & $(0 \%)$ & 900 & $(83 \%)$ & 0 & $(0 \%)$ & 0 & $(0 \%)$ \\
\hline Company D & 0 & $(0 \%)$ & 400 & $(18 \%)$ & 1160 & $(53 \%)$ & 0 & $(0 \%)$ & 40 & $(2 \%)$ \\
\hline Company E & 0 & $(0 \%)$ & 90 & $(4 \%)$ & 750 & $(34 \%)$ & 1100 & $(50 \%)$ & 0 & $(0 \%)$ \\
\hline Company F & 0 & $(0 \%)$ & 0 & $(0 \%)$ & 0 & $(0 \%)$ & 400 & $(100 \%)$ & 0 & $(0 \%)$ \\
\hline Company G & 0 & $(0 \%)$ & 0 & $(0 \%)$ & 1220 & $(58 \%)$ & 210 & $(10 \%)$ & 0 & $(0 \%)$ \\
\hline Company H & 0 & $(0 \%)$ & 0 & $(0 \%)$ & 0 & $(0 \%)$ & 680 & $(59 \%)$ & 0 & $(0 \%)$ \\
\hline Company I & 0 & $(0 \%)$ & 0 & $(0 \%)$ & 0 & $(0 \%)$ & 0 & $(0 \%)$ & 0 & $(0 \%)$ \\
\hline Company J & 0 & $(0 \%)$ & 0 & $(0 \%)$ & 1740 & $(81 \%)$ & 180 & $(8 \%)$ & 0 & $(0 \%)$ \\
\hline Company K & 0 & $(0 \%)$ & 0 & $(0 \%)$ & 3120 & $(77 \%)$ & 460 & $(11 \%)$ & 0 & $(0 \%)$ \\
\hline
\end{tabular}


From Table 6, it is evident that the largest energy saving potential is, as expected, found in the drying process. The average energy saving potential for the production processes with regard to the total EEU is $10 \%$ for the studied sawmills, in comparison to the average of $21 \%$ when considering all participating companies in the SEAP (Paramonova and Thollander, 2016). It is worth mentioning that, for all companies except one, the drying process (heat and electricity combined) accounts for over half of the proposed EEMs' energy saving potential. In other words, the energy auditors have focused on the drying process. Company $E$ has a large energy saving potential for the drying process. The amount of electricity saved is more than half the total electricity used in this process, corresponding to their high EEI value for drying (electricity).

Regarding De-barking and sawing, being the second largest production process in terms of energy use, three out of five companies with an EEl above one (1) had proposed EEMs. At the same time, company $\mathrm{A}$, with the lowest EEl for de-barking and sawing, had the second largest energy saving potential. However, the percentage of energy saved for this process was higher for both Company $D$ and Company $\mathrm{E}$ ( $27.5 \%$ and $8.5 \%$ respectively), but the EEMs in Company $\mathrm{B}$ and Company $\mathrm{C}$ might have been overlooked, or Company A's EEMs overestimated.

By comparing Figures 3 and 4 with Tables 5 and 6 , it is not possible to discern any correlation between resulting EEI and identified EEMs. For example, Company C'S EEU processes with highest EEI value were regrading, drying (heat) and de-barking and sawing, but their highest identified energy saving potentials were drying (heat), space heating and lighting. This is partly explained by the share of EEU for each process, where space heating is the third largest EEU process (Table 4) and regrading is one of the smaller processes. Nonetheless, a discrepancy still exists, suggesting that either the proposed method is unsuitable for identifying energy efficiency potentials or the quality of energy audits is low, or both. However, the energy auditors' experience and competence are likely to be diverse, as is the level of detail of each audit, which impacts the number of EEMs given. Also, as the data quality cannot be fully validated at times, the proposed EEMs might not be correctly categorized.

When comparing single processes between companies, the proposed method is similar to other methods proposed in the literature. However, when finding a total indexed value for the entire site, the method in this paper has a unique approach with the term PS $S_{i, j}$, where all processes included in the EEI are weighted into the total depending on the individual site's EEU for that process. In practice, some processes have a larger impact than others on the total EEI. This enables companies and auditors 
to use the EEI as a tool for energy management strategies, and shows where to focus energy efficient improvements. How this works is visualized in Figure 5, using Company E as an example.

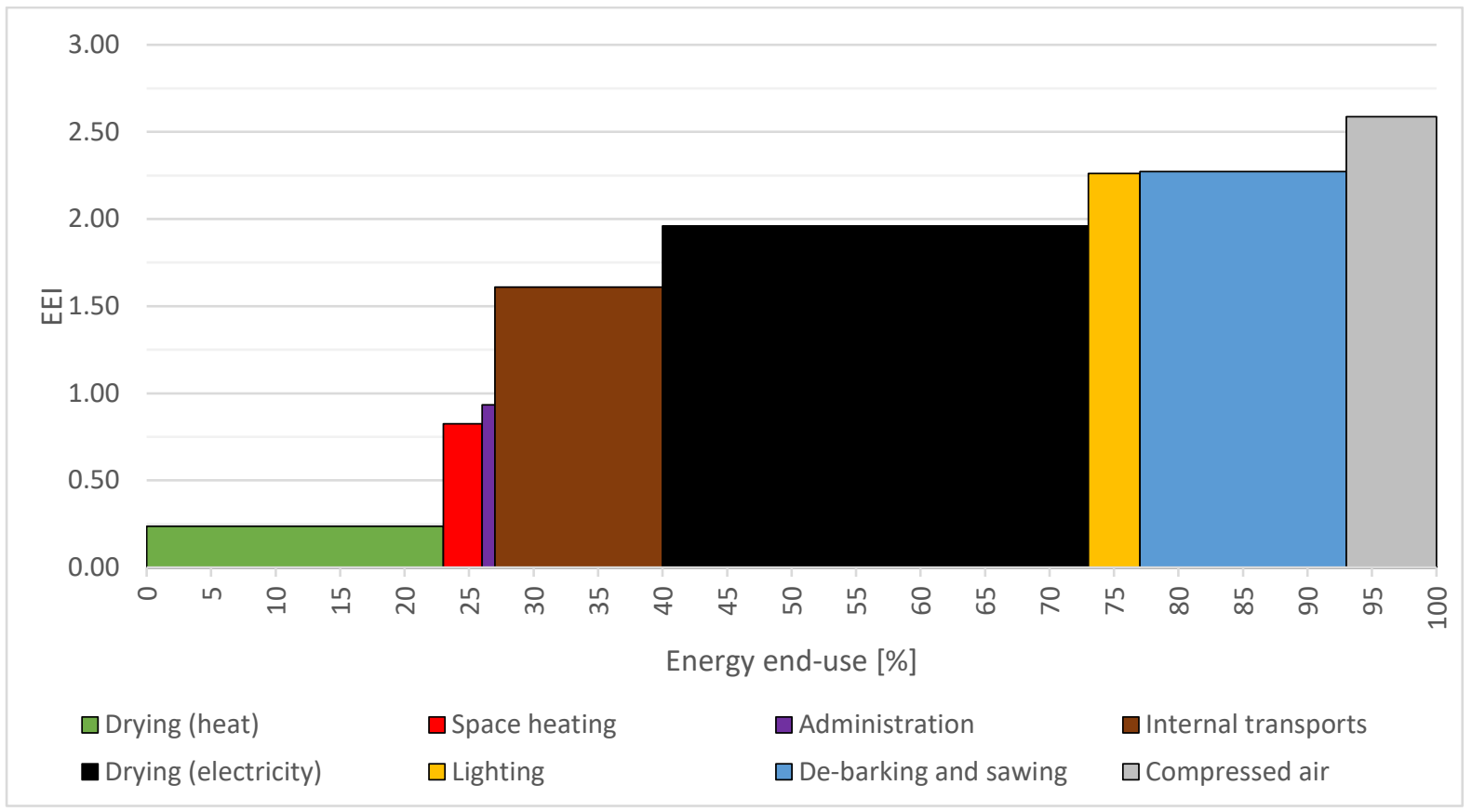

Figure 5: Visualization of how the proposed method can be used as an energy strategy tool by the individual company or auditor in a benchmarking context. The data presented regards Company E, serving as an example of how each of their EEU processes impacts the total EEI for the entire site, where the largest EEU process (Drying (electricity)) has the largest impact on the total EEI, etc.

Figure 5 provides an indication on what EEU processes a company should emphasize in their energy efficiency efforts. While compressed air has a high value in the EEI, it does not account for a large share of the total EEU, in contrast to e.g. drying (electricity), which seems to be less energy efficient in comparison with their peers. However, following this line of thought, drying (heat) seems to be the most energy efficient due to its low EEI, but comparing this with the energy saving potentials in Table 5 and Table 6, the magnitude of energy saving potential is (in descending order): drying (electricity), drying (heat), lighting, compressed air and de-barking and sawing. Hence, compressed air and drying (heat) still have energy efficiency potentials. From this, it is not clear how a company should prioritize their efforts, but as this is another discrepancy between the resulting index and the EEI it further emphasizes the importance of high quality data in order to scale-up and further evaluate the proposed method for calculating an EEI. If realized, the EEI can be a valuable asset for both companies and other actors in benchmarking the energy performance of individual EEU processes and sites.

\section{Concluding discussion}

A general method has been suggested for calculating an energy efficiency index (EEI) for benchmarking industrial companies' energy performance. This paper is a preliminary investigation of the developed method, which was applied to 11 industrial SMEs classified as NACE 16, using data from the Swedish Energy Audit Program (SEAP). The proposed EEI uses specific energy use (SEC) as a performance indicator and allows benchmarking of single energy end-use (EEU) processes as well as entire industrial sites. The method differs compared with existing methods in the literature. While benchmarking of industrial EEU processes has been carried out (e.g. by Laurijssen et al., 2013; Worrell and Price, 2006; Xu et al., 2009), applying a total EEI value for an industrial site by weighting each EEU process according to its percentage of total EEU, as in this paper, is to the authors' knowledge a new approach. By keeping the method relatively simple, it enables the use of the EEI as an energy management tool for industrial SMEs, and possibly also for larger companies, for implementation in their energy strategy in 
terms of the EEU processes on which to focus their energy efficiency efforts. A simple yet fair energy performance benchmarking tool has been called for by Kimura et al. (2015).

Since energy auditors are diverse in terms of their competence and experience, they might focus on EEU processes where they possess general and scalable knowledge. As noted by Sorrell (2007), the oftentimes small national energy service markets provide little emphasis for energy service providers to "dig deep" into sectors where up-front costs in gaining specific production process knowledge cannot be covered in later contracts, as the potential clients in one country are too few in number. In this regard, energy efficiency potentials might be overlooked. Benchmarking practices are therefore complementary to energy auditing, where process-level benchmarking has the possibility to identify inefficiencies and potentials for energy efficiency improvement (Ke et al., 2013).

To test whether the proposed method for calculating an EEI could serve as a benchmarking tool, a comparative analysis of the proposed method's resulting EEI and energy saving potentials given in energy audit reports was carried out for both entire sites and specific support and production processes. This analysis showed a discrepancy between the resulting EEI calculated by the paper's proposed method and the sawmills' energy saving potential. Thus, further evaluation of the proposed method should be done on a larger scale with high-quality data.

\subsection{Quality of energy data}

The quality of energy data is recognized as a major barrier to energy performance benchmarking (Boyd, 2016). This issue has been emphasized in this paper, as many errors in the reported energy data were discovered from the in-depth analysis of energy audits. It should be noted that multiple uncertainties, and possibly also undetected errors, still exist. Saygin et al. (2011) also found uncertainties in their data used to calculate EEls. In contrast, the data points in the dataset used by Laurijssen et al. (2013) were collected using a uniform format, collected by the companies themselves under the guidance of a single expert, using the same system and process boundaries, thus allowing a fairer comparison. This data collection procedure differs from the dataset in this paper, derived from SEAP, where energy auditors measured or estimated EEU and suggested measures, using different levels of detail and consequently proposing different numbers of EEMs. Furthermore, the EEU and measures were reported not by the auditors, but by the company. A joint system for measuring the EEU could improve data quality, as for Laurijssen et al. (2013), who had access to high-quality data from Dutch paper mills. Another means that was found in this paper for improving the data quality assurance process was that after the EEl is created, a validation can be carried out with the company concerned. This was not possible in the present study, but is proposed as a means to further enhance the quality of an EEI, and to improve data quality for specific companies.

Regarding EEU data in the database for the studied sample of companies, a few did not have a distribution of EEU for the support processes. For example, Company $\mathrm{G}$ had all its EEU for support processes in administration. Thus, the data had to be distributed across all support processes by the authors, based on the energy audit reports. A similar approach was necessary for Company D. For other companies, the EEU for certain support processes proved to be incorrect and thus some EEU data had to be reallocated, again by using the energy audit reports. This applies for companies $B, J$ and K.

For reported EEMs in the database, a common error was EEMs that should have been derived as space heating, but instead were categorized as measures for drying. This was found for four of the studied companies. Further, energy audit reports sometimes presented more than one option for the same measure, but both options' energy saving potentials were added together when reported. In practice, this leads to double-counting, as it is only possible to implement one of the measures. One example is found in Company G, where the auditors gave two different suggestions for a new lighting installation with the same energy saving potential. This was counted as a $60 \mathrm{MWh}$ energy saving potential in the database, but in reality only $30 \mathrm{MWh}$ could potentially be saved. 
This makes it hard to validate the proposed method by comparing the EEI values with the energy saving potential, since some values that have not been corrected may still exist.

\subsection{Key performance indicators for energy efficiency benchmarking}

In this paper, a categorization of production processes at sawmills (based on Olsson et al., 2011) with corresponding KPIs is suggested. Whether the proposed KPIs are the most suitable might be subject to further research. Relevant KPIs should ideally capture the companies' different prerequisites, such as the effect of moisture content on energy use in the drying process. While common standards exist to measure the moisture content, a more rigorous benchmarking requires a greater effort from companies, auditors and other actors. For industrial sectors characterized by SMEs, a benchmarking tool should be kept simple and easy to use.

Having said this, well-developed energy-related KPIs contribute to fairer benchmarking by including correction factors, and future research should therefore aim to validate both the categorization of processes and which indicators to use.

\subsection{Harmonization of energy end-use processes}

For residential buildings, Mathew et al. (2008) show the possibility of benchmarking EEU components through the use of comprehensive data for commercial buildings. To enable the same possibilities in the industrial sector, common metrics for, and a harmonized categorization of, industrial EEU at process level must be striven for. A harmonized taxonomy for production processes is called for by, for example, Thollander et al. (2015).

A harmonized categorization of the production processes for each industrial sub-sector could also be used as a protocol for energy auditors to divide the EEU. From the audits, a database could be developed, similar to the SEAP database but containing EEU categorization of production processes as well. Such a database has previously been proposed by Paramonova and Thollander (2016). This would allow a more accurate comparison between companies. In order to facilitate the creation of a detailed energy database, common definitions and boundaries for industrial processes need to be defined (Tanaka, 2008). It is therefore recommended that further research strives to categorize EEU of support and production processes in different industrial sectors.

The harmonized categorization of support and production processes in combination with quality assured energy data are prerequisites for a useful and effective EEI for benchmarking practices. The need for high-quality industrial energy data for benchmarking was noted by Laurijssen et al. (2013), but knowledge of the studied processes was also emphasized. Thus, even with a benchmarking value, it is still necessary to have adequate knowledge of the specific EEU processes in order to understand differentiating results.

\subsection{Application of the energy efficiency index}

Possible users of the proposed EEI include industrial companies and authorities with an auditing role. EU Member States, in line with the Industrial Emissions Directive (European Commission, 2010), are required to monitor industrial companies' compliance using best available techniques (BAT). In Sweden, these regulations are carried out by each county's administrative board. Historically, the emphasis on energy efficiency issues has differed between counties but has recently gained further attention through the "Incentives for Energy Efficiency" project (Swedish Energy Agency, 2016). This aims to combine environmental auditing with increased energy efficiency among SMEs.

The administrative boards' energy auditing could be facilitated by using a benchmarking tool, such as the EEI proposed in this paper. Each county administrative board's workload would be reduced by using a common model to collect data from industrial companies in different regions. Such a procedure would particularly support the county administrative boards where energy auditing has historically been a low priority. A joint effort regarding energy auditing across different counties is also beneficial in order to equalize competitive advantages among industrial companies, as the distinction 
of how much effort is put into energy auditing consequently implies what recommendations and requirements are set for companies. A similar use of the EEI might possibly exist for other EU Member States as well. Establishing specific industry benchmarking targets for companies to comply with is difficult, especially for SMEs, due to inhomogeneous processes. However, such practices have been conducted in Japan through the Energy Conservation Law, but so far only targets for energy-intensive industries have been set (Kimura et al., 2015).

The EEI proposed in this paper could be utilized by industrial SMEs, larger enterprises, and county administrative boards, in which the identification of EEMs is facilitated, taking a great step forward towards a competitive and more energy-efficient manufacturing industry.

\section{Acknowledgements}

The authors would like to thank the Swedish Energy Agency for funding research project no. 40537-1 in which this study has been conducted. We would also like to thank the anonymous referee whose comments helped to improve the quality of this paper. 


\section{References}

Aguirre, F., Villalobos, R.J., Phelan, P.E., Pacheco, R., 2010. Assessing the relative efficiency of energy use among similar manufacturing industries. Int. J. energy Res. 477-488.

Andersson, J., Lycken, A., Nordman, R., Olsson, M., Räftegård, O., Wamming, T., 2011. State of the art - Energianvändning i den svenska sågverksindustrin.

Azadeh, A., Amalnick, M.S., Ghaderi, S.F., Asadzadeh, S.M., 2007. An integrated DEA PCA numerical taxonomy approach for energy efficiency assessment and consumption optimization in energy intensive manufacturing sectors. Energy Policy 35, 3792-3806.

Backlund, S., Thollander, P., Palm, J., Ottosson, M., 2012. Extending the energy efficiency gap. Energy Policy 51, 392-396.

Bernard, J.-T., Côté, B., 2005. The measurement of the energy intensity of manufacturing industries: a principal components analysis. Energy Policy 33, 221-233.

Blomberg, J., Henriksson, E., Lundmark, R., 2012. Energy efficiency and policy in Swedish pulp and paper mills: A data envelopment analysis approach. Energy Policy 42, 569-579.

Boyd, G.A., 2016. Comparing the statistical distributions of energy efficiency in manufacturing: metaanalysis of 24 Case studies to develop industry-specific energy performance indicators (EPI). Energy Effic. 1-22.

Bunse, K., Sachs, J., Vodicka, M., 2010. Evaluating Energy Efficiency Improvements in Manufacturing Processes, in: Vallespir, B., Alix, T. (Eds.), Advances in Production Management Systems. New Challenges, New Approaches: IFIP WG 5.7 International Conference, APMS 2009, Bordeaux, France, September 21-23, 2009, Revised Selected Papers. Springer Berlin Heidelberg, Berlin, Heidelberg, pp. 19-26.

Bunse, K., Vodicka, M., Schönsleben, P., Brülhart, M., Ernst, F.O., 2011. Integrating energy efficiency performance in production management - Gap analysis between industrial needs and scientific literature. J. Clean. Prod. 19, 667-679.

Chung, W., 2011. Review of building energy-use performance benchmarking methodologies. Appl. Energy 88, 1470-1479.

Eggleston, M., 2015. Energy Benchmarking, in: Rossiter, A.P., Jones, B.P. (Eds.), Energy Management and Efficiency for the Process Industries. John Wiley \& Sons, Inc., Hoboken, New Jersey, pp. 5665.

ENERGY STAR, 2017. Benchmark energy use [WWW Document]. URL https://www.energystar.gov/buildings/about-us/how-can-we-help-you/benchmark-energyuse?s=mega (accessed 2.17.17).

European Commission, 2016. Proposal for a Directive of the European Parliament and of the Council amending Directive 2012/27/EU.

European Commission, 2015. Statistical Classification of Products by Activity, Version 2.1 [WWW Document]. URL ec.europa.eu/eurostat/ramon (accessed 1.18.17).

European Commission, 2012. Directive 2012/27/EU of the European Parliament and of the Council of 25 October 2012 on energy efficiency, Official Journal of the European Union Directive.

European Commission, 2010. Directive 2010/75/EU of the European parliament and of the council of 24 November 2010 on industrial emissions, Official Journal of the European Union. 
European Commission, 2009. Reference document on best available techniques for energy efficiency, European Commission.

Fleiter, T., Worrell, E., Eichhammer, W., 2011. Barriers to energy efficiency in industrial bottom-up energy demand models - A review. Renew. Sustain. Energy Rev. 15, 3099-3111.

Giacone, E., Mancò, S., 2012. Energy efficiency measurement in industrial processes. Energy 38, 331345.

Han, X., Xue, X., Ge, J., Wu, H., Su, C., 2014. Measuring the productivity of energy consumption of major industries in China: A DEA-based method. Math. Probl. Eng. 2014.

Hasanbeigi, A., Hasanabadi, A., Abdorrazaghi, M., 2012. Comparison analysis of energy intensity for five major sub-sectors of the Textile Industry in Iran. J. Clean. Prod. 23, 186-194.

Hirst, E., Brown, M., 1990. Closing the efficiency gap: barriers to the efficient use of energy. Resour. Conserv. Recycl. 3, 267-281.

International Energy Agency, 2014. Energy Efficiency Indicators: Essentials for Policy Making.

International Energy Agency, 2007. Tracking Industrial Energy Efficiency and CO2 Emissions.

Jaffe, A.B., Stavins, R.N., 1994. The energy-efficiency gap What does it mean? Energy Policy 22, 804810.

Kannan, R., Boie, W., 2003. Energy management practices in SME-case study of a bakery in Germany. Energy Convers. Manag. 44, 945-959.

Ke, J., Price, L., McNeil, M., Khanna, N.Z., Zhou, N., 2013. Analysis and practices of energy benchmarking for industry from the perspective of systems engineering. Energy 54, 32-44.

Kimura, O., Karlsson, M., Cornelis, E., Paramonova, S., Thollander, P., Morales, I., Navarro, J.J., Bertelsen, C.W., 2015. IEA IETS Annex XVI Energy Efficiency in SMEs Task III: Methods and tools to achieve energy efficiency in industrial SMEs.

Kvale, S., Brinkmann, S., 2009. Den kvalitativa forskningsintervjun. Lund : Studentlitteratur, 2009.

Laurijssen, J., Faaij, A., Worrell, E., 2013. Benchmarking energy use in the paper industry: a benchmarking study on process unit level. Energy Effic. 6, 49-63.

Mateos-Espejel, E., Savulescu, L., Maréchal, F., Paris, J., 2010. Base case process development for energy efficiency improvement, application to a Kraft pulping mill. Part II: Benchmarking analysis. Chem. Eng. Res. Des. 9, 729-741.

Mathew, P., Mills, E., Bourassa, N., Brook, M., 2008. Action-oriented benchmarking: Using the CEUS database to benchmark commercial buildings in California. Energy Eng. 105, 6-18.

May, G., Barletta, I., Stahl, B., Taisch, M., 2015. Energy management in production: A novel method to develop key performance indicators for improving energy efficiency. Appl. Energy 149, 46-61.

Meyers, S., Schmitt, B., Chester-Jones, M., Sturm, B., 2016. Energy efficiency, carbon emissions, and measures towards their improvement in the food and beverage sector for six European countries. Energy 104, 266-283.

Mills, E., 2016. Action-Oriented Energy Benchmarking for Nonresidential Buildings, in: IEEE. pp. 697712.

Morfeldt, J., Silveira, S., 2014. Capturing energy efficiency in European iron and steel productioncomparing specific energy consumption and Malmquist productivity index. Energy Effic. 7, 955- 
972.

Nouri, J., Lotfi, H.F., Borgheipour, H., Atabi, F., Sadeghzadeh, S.M., Moghaddas, Z., 2013. An analysis of the implementation of energy efficiency measures in the vegetable oil industry of Iran: a data envelopment analysis approach. J. Clean. Prod. 52.

ODYSSEE-MURE, 2017. Project overview [WWW Document]. URL http://www.odysseemure.eu/project.html (accessed 1.25.17).

Oh, S.C., Hildreth, A.J., 2014. Estimating the Technical Improvement of Energy Efficiency in the Automotive Industry-Stochastic and Deterministic Frontier Benchmarking Approaches. ENERGIES.

Olsson, M., Lycken, A., Nordman, R., 2011. Dokumentation till sågverksmodellen inom projekt EESI EnergiEffektivisering i SågverksIndustrin.

Paramonova, S., Thollander, P., 2016. Ex-post impact and process evaluation of the Swedish energy audit policy programme for small and medium-sized enterprises. J. Clean. Prod. 135, 932-949.

Paramonova, S., Thollander, P., Ottosson, M., 2015. Quantifying the extended energy efficiency gapevidence from Swedish electricity-intensive industries. Renew. Sustain. Energy Rev. 51, 472-483.

Peterson, R.D., Belt, C.K., 2009. Elements of an energy management program. J. Miner. Met. Mater. Soc. $61,19-24$.

Prashar, A., 2017. Adopting PDCA (Plan-Do-Check-Act) cycle for energy optimization in energyintensive SMEs. J. Clean. Prod. 145, 277-293.

Rietbergen, M.G., Blok, K., 2010. Setting SMART targets for industrial energy use and industrial energy efficiency. Energy Policy 38, 4339-4354.

Saygin, D., Worrell, E., Patel, M.K., Gielen, D.J., 2011. Benchmarking the energy use of energy-intensive industries in industrialized and in developing countries. Energy 36, 6661-6673.

Schulze, M., Nehler, H., Ottosson, M., Thollander, P., 2016. Energy management in industry: a systematic review of previous findings and an integrative conceptual framework. J. Clean. Prod. $112,3692-3708$.

Skog, J., Vikberg, T., Oja, J., 2010. Sapwood moisture-content measurements in Pinus sylvestris sawlogs combining X-ray and three-dimensional scanning. Wood Mater. Sci. Eng. 5, 91-96.

Sorrell, S., 2007. The economics of energy service contracts. Energy Policy 35, 507-521.

Spiering, T., Kohlitz, S., Sundmaeker, H., Herrmann, C., 2015. Energy efficiency benchmarking for injection moulding processes. Robot. Comput. Integr. Manuf. 36, 45-59.

Swedish Energy Agency, 2017. Energy in Sweden, Fact and Figures 2017. Eskilstuna: Sweden.

Swedish Energy Agency, 2016. Incitament för energieffektivisering [WWW Document]. URL http://www.energimyndigheten.se/nrp/incitament-for-energieffektivisering/ (accessed 4.13.17).

Swedish Forest Agency, 2014. Swedish Statistical Yearbook of Forestry. Swedish Forest Agency, Sweden, Jönköping.

Swedish Standards Institute, 2012a. SS-EN 16231:2012 Energy efficiency benchmarking methodology.

Swedish Standards Institute, 2012b. SS-EN 16212:2012 Energy Efficiency and Savings Calculation, Topdown and Bottom-up Methods. 
SWEREA, 2017. ENIG - Nyckeldatabasen [WWW Document]. URL https://www.swerea.se/samverkan/natverk/ENIG/nyckeldatabasen (accessed 5.17.17).

Söderström, M., 1996. Industrial Electricity Use Characterized by Unit Processes - A Tool for Analysis and Forecasting, in: Proc. of the 13th International Congress on Electricity Applications. June 1620, Birmingham UK.

Tanaka, K., 2008. Assessment of energy efficiency performance measures in industry and their application for policy. Energy Policy 36, 2877-2892.

Taylor, A.M., Garner, B.L., Morrell, J.J., 2002. Heartwood formation and natural duraility - a review. Wood Fiber Sci.

Thollander, P., Paramonova, S., Cornelis, E., Kimura, O., Trianni, A., Karlsson, M., Cagno, E., Morales, I., Jimenez Navarro, J.P., 2015. International study on energy end-use data among industrial SMEs (small and medium-sized enterprises) and energy end-use efficiency improvement opportunities. J. Clean. Prod. 104, 282-296.

Towslee, J.S., 2015. Energy Management Key Performance Indicators (EnPIs) and Energy Dashboards, in: Rossiter, A.P., Jones, B.P. (Eds.), Energy Management and Efficiency for the Process Industries. John Wiley \& Sons, Inc., Hoboken, New Jersey, pp. 349-360.

Viesi, D., Pozzar, F., Federici, A., Crema, L., Mahbub, M.S., 2017. Energy efficiency and sustainability assessment of about 500 small and medium-sized enterprises in Central Europe region. Energy Policy 105, 363-374.

Wang, N., Wen, Z., Liu, M., Guo, J., 2016. Constructing an energy efficiency benchmarking system for coal production. Appl. Energy 169, 301-308.

Wilson, D., Swisher, J., 1993. Exploring the gap: top-down versus bottom-up analyses of the cost of mitigating. Energy Policy 21, 249-263.

Worrell, E., Price, L., 2006. An Integrated Benchmarking and Energy Savings Tool for the Iron and Steel Industry. Int. J. Green Energy 3, 117-126.

Xu, T., Flapper, J., Kramer, K.J., 2009. Characterization of energy use and performance of global cheese processing. Energy 34, 1993-2000.

Xue, X., Wu, H., Zhang, X., Dai, J., Su, C., 2015. Measuring energy consumption efficiency of the construction industry: The case of China. J. Clean. Prod. 107, 509-515.

Önüt, S., Soner, S., 2007. Analysis of energy use and efficiency in Turkish manufacturing sector SMEs. Energy Convers. Manag. 48, 384-394. 